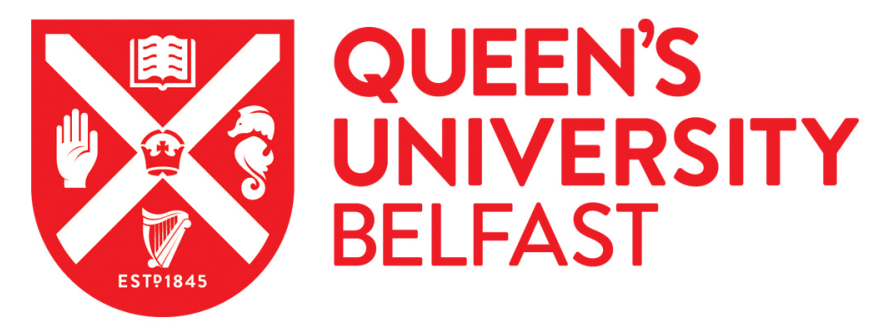

\title{
Childbearing through the Lens of Women with Minor Thalassemia: A Qualitative Study
}

Khadijeh, S., Behboodi Moghadam, Z., Khadijeh, N. M., Millen, S., \& Mohsen, S. (2019). Childbearing through the Lens of Women with Minor Thalassemia: A Qualitative Study. Galen Medical Journal, 8, e1429. [e1429]. https://doi.org/10.31661/gmj.v8i0.1429

\section{Published in:}

Galen Medical Journal

Document Version:

Publisher's PDF, also known as Version of record

Queen's University Belfast - Research Portal:

Link to publication record in Queen's University Belfast Research Portal

Publisher rights

2019 The Authors.

This is an open access article published under a Creative Commons Attribution License (https://creativecommons.org/licenses/by/4.0/), which permits unrestricted use, distribution and reproduction in any medium, provided the author and source are cited.

\section{General rights}

Copyright for the publications made accessible via the Queen's University Belfast Research Portal is retained by the author(s) and / or other copyright owners and it is a condition of accessing these publications that users recognise and abide by the legal requirements associated with these rights.

Take down policy

The Research Portal is Queen's institutional repository that provides access to Queen's research output. Every effort has been made to ensure that content in the Research Portal does not infringe any person's rights, or applicable UK laws. If you discover content in the Research Portal that you believe breaches copyright or violates any law, please contact openaccess@qub.ac.uk. 


\title{
ORIGINAL \\ ARTICLE
}

Received

Revised

Accepted
2018-11-24

2018-12-21

2019-01-21

\section{Childbearing through the Lens of Women with Minor Thalassemia: A Qualitative Study}

\author{
Khadijeh Sarayloo ${ }^{1}$, Zahra Behboodi Moghadam², Khadijeh Mirzaii Najmabadi' ${ }^{1 凶}$, Sharon Elizabeth Millen ${ }^{3}$, \\ Mohsen Saffari ${ }^{4,5}$
}

\begin{abstract}
${ }^{1}$ Nursing and Midwifery Schools, Mashhad University of Medical Sciences, Mashhad, Iran
${ }^{2}$ Reproductive Health Department, School of Nursing and Midwifery, Tehran University of Medical Sciences, Tehran, Iran ${ }^{3}$ New Baby Programme, Centre for Evidence \& Social Innovation (CESI), School of Social Sciences, Education and Social Work, Queen's University Belfast, United Kingdom

${ }^{4}$ Health Research Center, Life Style Institute, Baqiyatallah University of Medical Sciences Tehran, Iran

${ }^{5}$ Health Education Department, School of Health, Baqiyatallah University of Medical Sciences, Tehran, Iran
\end{abstract}

\begin{abstract}
Background: It is essential to provide key information and support to every woman regarding pregnancy and childbirth to enable all women to make a fully informed decision regarding their choice to reproduce. Of particular importance; however, is that women who suffer from a specific condition that increases risks associated with reproduction, to receive specific information regarding such risks and health complications regarding pregnancy and childbirth. This study aims to explore the feelings, experiences, and needs of women with minor thalassemia in relation to childbearing. Materials and Methods: This sample comprised of 12 Iranian women with minor thalassemia who attended to local health centers in Minudasht, Golestan province, from October 2017 to January 2018. The purposeful sampling technique was employed. The data were collected through deep semi-structured interviews, analyzed using conventional content analysis and processed by using the Graneheim and Lundman method. Results: The findings were based on the participants' experiences of pregnancy and fertility. Three major themes emerged; 'Emotional and Physical Experience,' 'Satisfaction' and 'Social and Cultural Issues.' The most common problem identified was the impact of emotional problems and difficulties regarding the negative implications of thalassemia on reproduction as well as the views and perceptions of family members and those within the community. Conclusion: From the findings, it is evident that thalassemia imposes a heavy psychosocial burden on those women who suffer from the condition. Local health centers in areas most affected by thalassemia would be considered the most suitable venues to introduce key health educational interventions. [GMJ.2019;8:e1429] DOI:10.31661/ami.v8i0.1429
\end{abstract}

Keywords: Thalassemia; Pregnancy; Qualitative Research; Iran

\section{GMJ}

Copyright $\odot$ 2019, Galen Medical Journal. This is an open-access article distributed under the terms of the Creative Commons Attribution 4.0 International License (http://creativecommons.org/licenses/by/4.0/) Email:info@gmj.ir

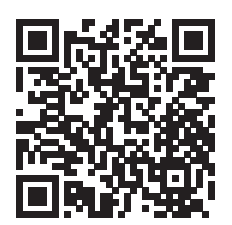

Correspondence to:

Khadijeh Mirzaii Najmabadi, Associate Professor, Nursing and Midwifery School, Mashhad University of Medical Sciences, Mashhad, Iran Telephone Number: +98-5138598016

Email Address: mirzaiikh@mums.ac.ir 


\section{Introduction}

$\mathrm{T}$ halassemia is the most common hereditary disease in the world. Approximately $6 \%$ of the global populations are carriers of the $\beta$-thalassemia mutant gene [1]. The areas of highest prevalence are in North and South Iran, particularly within the Golestan and Mazandaran provinces where prevalence rates of those affected are between $10 \%$ to $13 \%$ [2]. Thalassemia poses a remarkable impact on women's lives in physical, psychological, and social aspects [3]. The added stress of pregnancy, for example, can cause a deterioration of maternal status [4] exposure to subfertility and frequent abortions, $[5,6]$ a demand for ovulation stimulation and intrauterine fertilization [7]. Other related consequences include unwanted pregnancies, increased risk of maternal and fetal complications, abnormal pregnancy outcomes, preterm labor and a higher risk of requiring a cesarean section $[6$, $8,9]$. Cultural and social factors, in general, can have a large impact on the value and belief system of those within certain communities, in terms of health, life, happiness, family continuity and race $[10,11]$, including views and expectations regarding childbearing [12]. The cultural and societal value and expectation placed upon childbearing, not only can it largely motivate women to reproduce but often dictates the number of babies she is expected to produce [13-15]. Those women with minor thalassemia are often afraid and apprehensive about the prospect of falling pregnant because of the increased likelihood of their child having major thalassemia. Despite this fear; however, those affected are often impelled to child bear because of the strong influence of their cultural expectations and views [16-19]. It is therefore imperative to equip women with relevant information via targeted reproductive health education-focused interventions so as they can, in turn, develop and thus demonstrate more autonomy over their own informed decision-making regarding their desire to fall pregnant, while considering all potential health risks and complications involved. However, for achieving this aim, the active engagement and participation of those affected are essential. Therefore, these women must be encouraged to attend target- ed health education interventions by placing more value on the importance of healthcare rather than social and cultural expectations. Potential methods of achieving this would be to provide key information leaflets to all those affected via General physicians at the health centers or to distribute a community-wide mail drop of information leaflets. Previous qualitative research to date in relation to thalassemia has focused largely on the severe biological, and social impact of childbearing on women affected, including infertility, prenatal diagnosis and/ or pre-term labor. However, in recent years, there has been a growing interest specifically on childbearing and the impact of thalassemia [15, 20-22]. In general, women experience various degrees of acceptance and attachment in relation to their unborn child and can perceive and express their pregnancy experience in several contrasting ways, largely dependent upon specific circumstances regarding the pregnancy. These circumstances are largely dependent upon a wide range of social contexts, which can differ significantly in terms of material, cultural resources and constraints [23, 24]. The autonomy of women as to whether they make an informed decision to fall pregnant, as well as their motivation for childbearing, is different in every context $[16$, 20]. The way in which women with minor thalassemia experience childbearing has not been investigated to date in Iran. Therefore, it is crucial to explicitly establish the feelings and perception of those women affected in terms of their fears, concerns and perceived level of support required regarding the experience of pregnancy and childbearing within a safe neutral environment. This study aims to contribute to this significant gap in the literature by exploring the feelings, experiences, and needs of women with minor thalassemia in relation to childbearing in Iran.

\section{Materials and Methods}

A qualitative study was conducted using a deep semi-structured interview approach to explore in depth, the women's' experience of childbearing. The data was obtained objectively from participants without the use of leading questions or personal bias. A conventional content analysis approach was employed. The 
research questions were as follows:

1 - What is the experience of childbearing and pregnancy for women affected by minor thalassemia?

2- What are the views of women affected by thalassemia regarding pregnancy and childbearing?

\section{Setting}

The study was carried out at Minudasht health center in Golestan province, in Iran.

\section{Participants}

Women with minor thalassemia (whose husbands also had the condition) were selected by using purposeful sampling. All the women were of Iranian origin. Women were invited to participate in a face-to-face interview regarding their views, experience of pregnancy and childbearing. In total, 12 women agreed to be contacted again by the researcher with the view of consenting to take part in the study. Data saturation was reached by the 12 interviews, and thus recruitment ended at that point. The study's inclusion criteria were as follows: Married women with minor thalassemia (whose husbands also had the condition), aged between 15 to 49 years old, patients under the supervision of Minudasht health center, had a history of at least one pregnancy, consented to participate in the research. Notably, five women out of the sample of 12 (42\%) had already undergone an abortion due to the unborn child having major thalassemia.

\section{Data Collection}

Recruitment and data collection took place between October 2017 and January 2018 after permission from the Ethics Committee of Mashhad University of Medical Sciences was granted (ethical code: IR.MUMS. REC.1396.6). The purposeful sampling technique employed aimed to capture a significant contrast in terms of variations in experience. All participants were aware of the purpose and method of the study, and written consent was obtained from each participant prior to the interview. The interviews were conducted by the first author and recorded with the permission of the participants and took place in a location of the woman's choice (most often in a private room in the health center) and last- ed between 35-50 minutes. At the beginning of the interview, each participant was asked a series of demographic questions (Tabe-1). The interview then continued with a broad in-depth question relating to the woman's individual experience of pregnancy/pregnancies and, thereafter, a semi-structured schedule was employed to address further questions. Prompts were provided when required to ensure that all topics were discussed. A sample of the interview questions are in Table-1. In all interviews, participants were encouraged to speak freely about their experiences of pregnancy. All the interview recordings were transcribed verbatim and then encoded initially by the first author upon completion. After analysis of each interview, a subsequent interview was conducted with the next participant.

\section{Data Analysis}

The data were analyzed using the conventional content analysis approach and processed using the Graneheim and Lundman method [25] as follows:

1- First, the interviews were conducted at the earliest opportunity after recruitment and consent obtained. After 12 interviews, complete data saturation was achieved. Upon the completion of each interview, the recording was listened to several times to ensure that the interview content was accurately transcribed.

2- The data was then analyzed

3- The text of the interviews were divided into several meaningful units and then coded.

4- The units of meaning were summarized and derived in code form.

5- The codes were grouped based on similarities and differences under the same themes and sub-categories.

6- Coding and analysis were completed by hand over several months. Initial coding schemes were developed based on the interview guides and existing literature and were subsequently adapted and updated upon the completion of successive interviews and coding process. Four members of the research team independently double-coded several transcripts and then met to resolve coding differences through discussion, agreement, and development of new codes. MAXQDA10 was used to organize the data, code transcripts, and generate reports. For this analysis, we focused 


\section{Interview Questions}

1. Express your understanding and experience of pregnancy;

2. What are your feelings in terms of women with minor thalassemia falling pregnant?

3. What are the conditions of pregnancy for women with thalassemia? If you consider it to be difficult, how difficult is it?

4. How did thalassemia affect your pregnancy?

on each individual's experiences and views of childbearing.

\section{Trustworthiness}

Every attempt was made to capture the essence of the phenomenon for the participants as a whole while staying close to individuals' experiences. After each interview, the interviewers recorded their impressions and reactions of the participant. Researcher memos were later reviewed and compared with the data. An audit trail, with regards to the protocol and records kept regarding any deviation from such, was implemented at the beginning of the research project [26]. To ensure the accuracy of the data, the proposed criteria of Lincoln and Guba were applied [27]. Lincoln and Guba (1985) suggested that the value of a qualitative research study is strengthened by its trustworthiness. Trustworthiness involves establishing credibility or confidence in the "truth" of the findings; transferability or ability to apply the results to other contexts; dependability or showing consistent findings that can be repeated and; confirmability or the extent to which the findings are shaped by the participants views and not skewed by researcher bias, motivation, or interest. Credibility was confirmed by studying the participants' and researchers' reviews, asking a number of participants to review the interview transcripts and the derived codes to confirm as to whether they were an accurate representation of their experiences. Data transferability was confirmed by explicitly providing detailed information regarding participants' characteristics as well as the method of data collection and analysis, while also providing examples of the participant interview questions to allow others to replicate the research [27].

\section{Results}

\section{Demographic Characteristics}

The mean age of the 12 participants interviewed was 35 years (ranged 20-45 years). Five women reported that they already had one abortion because of major thalassemia. Of the 12 participants, three women worked as midwives while eight were housewives. One participant was illiterate. The demographic characteristics of the study's participants are listed in Table-2. Three major themes were extracted from the data (Table-3). These themes included: 'Emotional and Physical Experience,' 'Satisfaction' and 'Social and Cultural Issues.'

\section{Emotional and Physical Experience}

The most common response provided by participants regarding their childbearing and pregnancy experience was that of wanting to have someone to love them. Data related to this theme were identified by further questioning the participants to discuss their experiences of undergoing pregnancy with thalassemia. This theme included two sub-categories; negative psychological feelings and physical problems faced by women with minor thalassemia.

2.1. Negative Psychological Feelings and Physical Problems

Several women emphasized concerns of having to endure specific physical problems associated with their pregnancy. For example, one stated: "When I was pregnant, it was so hard for me. It was very difficult to test. After testing, I had to rest at home for a week; I felt a lot of pain and stress; I was in bed because of fearing the prospect of abortion. During the 


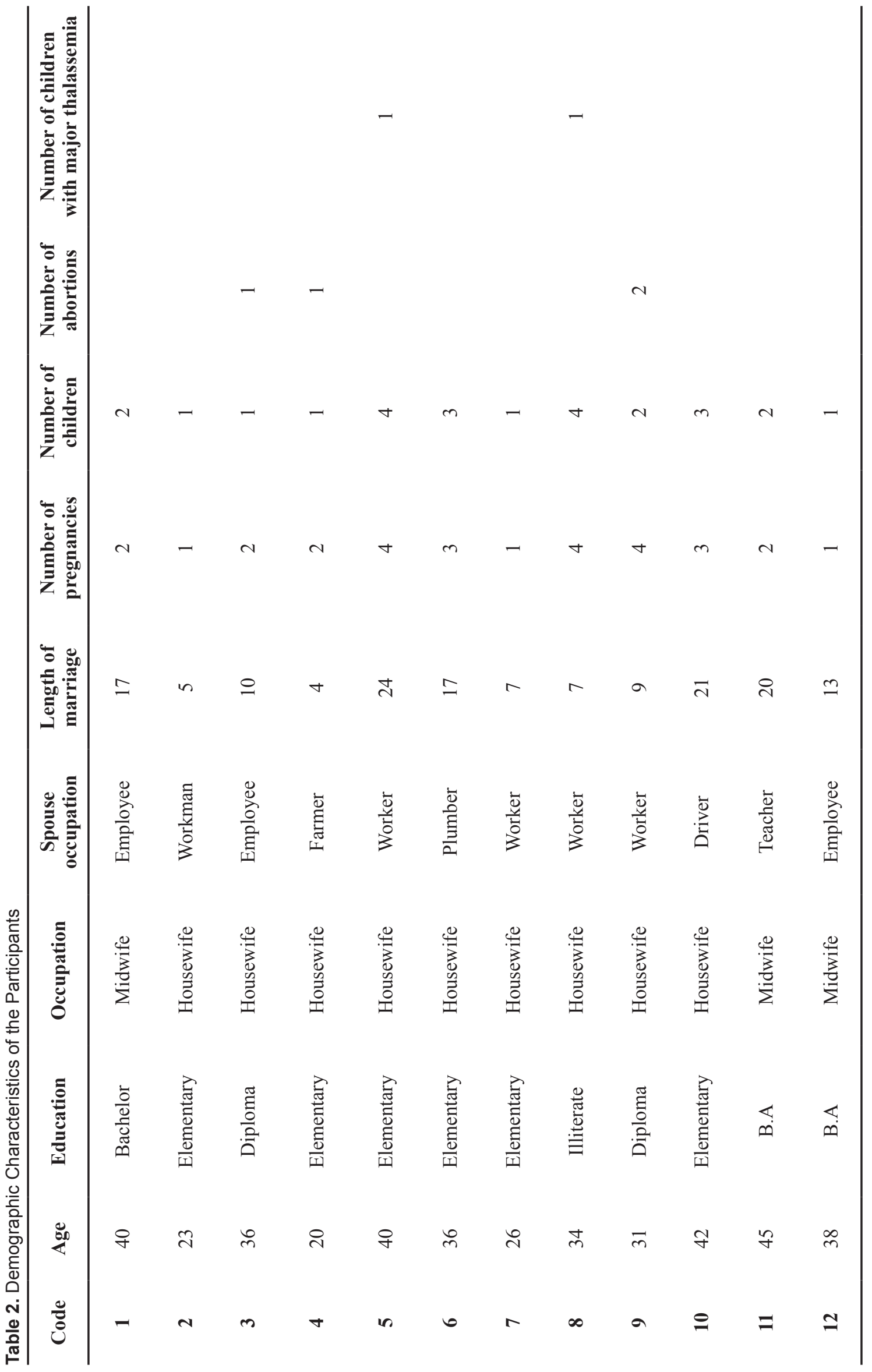


Table 3. Categories, Sub-Categories, and Themes for Mothers' Pregnancy Experiences with Minor Thalassemia

\begin{tabular}{|c|c|c|}
\hline Theme & Sub-Category & Related topics \\
\hline \multirow{12}{*}{$\begin{array}{l}\text { Emotional and physical } \\
\text { experience }\end{array}$} & \multirow{7}{*}{$\begin{array}{c}\text { Negative } \\
\text { psychological } \\
\text { feelings }\end{array}$} & Stress and anxiety \\
\hline & & $\begin{array}{l}\text { Discomfort and being afraid that the child may carry } \\
\text { the disease }\end{array}$ \\
\hline & & Regret \\
\hline & & Low self-confidence \\
\hline & & Concerned about forced abortion \\
\hline & & Worry \\
\hline & & Mental pressure \\
\hline & \multirow{5}{*}{ Physical problems } & Painfulness of the test \\
\hline & & Mother's weakness \\
\hline & & Symptoms of intense nausea and dizziness \\
\hline & & Difficult pregnancy \\
\hline & & Physical difficulty related to abortion \\
\hline \multirow{11}{*}{ Satisfaction } & \multirow{4}{*}{ The feeling of value } & The feeling of motherhood \\
\hline & & The feeling of pride \\
\hline & & Rising dignity \\
\hline & & Enjoyable pregnancy \\
\hline & \multirow{4}{*}{ Stability of family } & Improved marital relationship \\
\hline & & Collaboration and attention of the spouse \\
\hline & & $\begin{array}{c}\text { The spouse's feeling of responsibility owing to } \\
\text { childbirth }\end{array}$ \\
\hline & & The family encouragement \\
\hline & \multirow{3}{*}{ Spiritual support } & Resort to God \\
\hline & & Thank god \\
\hline & & Pray \\
\hline \multirow{7}{*}{$\begin{array}{l}\text { Social and cultural } \\
\text { issues }\end{array}$} & \multirow{4}{*}{ Social issues } & Low awareness of the community \\
\hline & & The family disagreement \\
\hline & & People’s negative view \\
\hline & & Stay at home all the time \\
\hline & \multirow{3}{*}{ Cultural issues } & Poor culture of People \\
\hline & & Stigma \\
\hline & & People's wrong beliefs \\
\hline
\end{tabular}

test, I was worried about touching the needle in the baby" (Interviewee Code 3). One of the participants who had to abort her pregnancy because of a prenatal diagnosis of major thalassemia described her experience of pregnancy as follows: "It was very hard to me. I had fulltime stress about health of my baby. When I became pregnant, I had to be tested. I realized that my baby had major thalassemia and so I had to abort it. My husband was upset and left the clinic, but I had to wait and go for a personal consultation. I was disappointed and had to abort my baby... It was so hard for me, both physically and mentally..." (Interviewee Code 8). Others reported that they had experienced physical complications during pregnancy and required special care. One participant for example, who was a midwife, expressed her feeling about her pregnancy as follows: "During pregnancy because of problems, such as dizziness and anemia, my general wellbeing was affected. I was not prepared 
and did not take folic acid. From this point of view, it was a bit hard to accept my pregnancy. After I accepted my pregnancy and continued it, I had nausea and dizziness in the first four months. I wasn't happy to experience it..." (Interviewee Code 11).

\section{Satisfaction}

Satisfaction emerged as another important main theme. Mothers discussed the feelings and emotions relating to their experience of childbearing. To also ascertain the general impact of thalassemia on childbearing, women were asked to talk about their feelings regarding women with minor thalassemia becoming pregnant. This theme includes the following three sub-categories: the feeling of value, the stability of the family and spiritual support.

\subsection{The Feeling of Value}

In general, the participants reported that they enjoyed their pregnancies without thinking about thalassemia. For instance, one participant said: "I had a great feeling of pride, when I realized I was pregnant" (Interviewee Code 8).

Some women felt elated at the prospect of the motherhood experience

One participant stated: "I had a great feeling regarding motherhood. It was a great energy, like my life was warming up. If you have no baby, you have no home... A baby makes life better, and you're going to progress" (Interviewee Code 8).

\subsection{Stability of Family}

The next sub-category was the stability of the family, which reflected the family's response and support provided regarding the woman's pregnancy. One of the participants stated: " $A$ baby plays a very important role in the relationship between the husband and wife. When my child was born, my marital relationship improved and became more intimate, and my marital life became stronger than before the arrival of my child" (Interviewee Code 6).

\subsection{Spiritual Support}

Spiritual support (which includes beliefs and other spiritual and religious issues) was identified as another sub-category of 'Satisfaction' - this was one of the most important aspects of these women's responses to being pregnant. Women expressed that their belief in God helped them to better cope during pregnancy. One woman stated: "I had no idea. I believe in God. When I found out I was pregnant, the doctor asked me to have an abortion because of thalassemia, I was so upset and prayed to God a lot. My husband wouldn't agree to the abortion. We were put under the supervision of a doctor, and he advised us to take a medication before prenatal testing. I kept praying for a healthy baby" (Interviewee Code 2).

\section{Social and Cultural Issues}

Social and cultural issues emerged as a third main theme as it was regarded by participants as a significant factor that greatly influenced the suffering of women with thalassemia. It comprised of two sub-categories, which separated social issues from cultural issues. An important factor that influenced these women's experiences was the reaction of the community and family. This had a great psychological effect on their perception of their pregnancy.

\subsection{Social Issues}

Acceptance of the condition by others within the community as well as having to deal with those women without the condition who experienced normal pregnancies were important factors. One participant described her friends and neighbors' view of her pregnancy as: "People say that when women with thalassemia become pregnant, they pray and hope to have healthy babies. My friends said to me: why did you become pregnant again? You're sick, and your baby won't be healthy. I became upset and distracted. The community's view was not good" (Interviewee Code 8). The views of some participants regarding social factors were as follows: "People have a different opinion. They think we should not have baby. People have a low level of literacy; they know very little about thalassemia and have a negative attitude toward this disease" (Interviewee Code 5).

\subsection{Cultural Issues}

Cultural issues are important factors that affected the participants. One woman reported: "Perception of people about us isn't good. They think that we shouldn't become pregnant 
because of thalassemia. They believe that the child will be ill, so we do not have the right to become pregnant since we would spend a lot financially if we got pregnant. There is no culture..." (Interviewee Code 6).

\section{Discussion}

To our knowledge, this is the first study in Iran which has explored the individual views and experiences of mothers with minor thalassemia regarding childbearing. Because of its exploratory and qualitative design, the present study has contributed to the identification of significant issues relating to the experience and views of women with minor thalassemia regarding their childbearing and pregnancy experience. The study employed a qualitative approach to obtain rich, in-depth data, particularly from an exploratory perspective of the mothers' experience and views. There have been several studies conducted using a range of methodologies and samples regarding views and experiences of motherhood and childbearing.

\section{Emotions and Physical Experience}

Aujulat et al. (2010), for instance, conducted a study which aimed to better understand the views of adolescent mothers regarding their experiences of pregnancy and motherhood. Several of the participants stated that they felt valued after childbearing because for them, motherhood created a sense of maturity and responsibility. The findings, in general, indicated that adolescents were delighted and proud of becoming a mother [28]. Our findings from this present study in part concur with those of Aujulat et al. [28] as the majority of participants were generally excited about their pregnancy and had a sense of satisfaction because of becoming pregnant, despite the increased risks associated with their health condition.

\section{Support}

In the present study, the support category was an important aspect mentioned by the participants. The results demonstrate that thalassemia can have a substantial effect on the emotional and social lives of those affected. In general, participants perceived thalassem- ia as a distressing condition that negatively impacted their childbearing experience and social lives. Women with thalassemia experience physical and psychological problems and often struggle to meet the needs of their child without the support of others. According to our findings, participants highlighted the desire and necessity for the provision of a comprehensive support system both within the home and throughout their community. Therefore, spousal, familial and societal support can have a significant positive effect on the physical and mental wellbeing of those affected. This particular aspect of the findings concurs with previous studies that have found similar concerns $[29,30]$. The consensus from these previous studies was that health care interventions must provide psychological support for women with thalassemia to facilitate the use of better coping strategies in relation to their distress regarding having minor thalassemia. The provision of support for these women is imperative given the rigid views and expectations of the culture and society in which they live. Our findings also concur with a study by Abdul et al. [31] that investigated the impact of thalassemia upon patients and their families. The findings indicate that thalassemia can have a significant negative psychosocial impact both upon patients and family members. This again emphasizes the need for the availability of social and psychological support services. Another significant finding from this research was the women's desire for information; they spoke extensively about their educational needs which were generally very limited, particularly in terms of the facts and knowledge regarding their condition. These findings are consistent with previous studies [32, 33] where mothers reported the need for information about the condition thalassemia, what causes it, what the health risks are and how it can be prevented. Lack of knowledge about thalassemia and its treatment has thus been demonstrated through our findings and similar studies to cause unnecessary anxiety and emotional distress among women and their families [34]. Therefore, the implementation of tailored health educational programs that include professional psychosocial support and located within the health centers is strongly recommended. The results 
of this study, similar to other qualitative studies, are not generalizable to all those women affected with minor thalassemia due to its exploratory nature and small sample size $(n=12)$ all of which came from the same geographical area.

\section{Conclusion}

There is a wealth of previous studies that have focused on thalassemia. However, most of these studies employed a quantitative design and thus did not have the rich in-depth qualitative data derived from the interview regarding women's own views, experiences, perceptions, feelings and the importance of support. This rich data provides a much deeper understanding of the concept and the main concerns that those affected have to endure. These themes and subcategories can be used as a structure for a larger multi-site study with a sufficient sample size for the findings to be generalizable to this patient group as a whole. These findings highlight that it is of upmost importance to provide health education and support interventions including professional psychosocial support. Psychosocial support is necessary for women to accept their pregnancy, i.e., through the validation and support of family and others. The stigma associated with thalassemia is one of the main obstacles to the disclosure of having the condition resulting in failure to receive adequate care during pregnancy. Childbearing was also found to be a major feature in the status and fertility of women within Iran. Thus, a recommendation from our findings is the provision of psychologists and/ or trained counselors specific to this patient group to be available within the health education interventions to address the issue of mental health. These programmes would aim to increase people's awareness about thalassemia and its prevention community-wide.

\section{Acknowledgment}

This study was supported by the Vice-chancellor for Research \& Technology of Mashhad University of Medical Sciences (grant number: 951364).

\section{Conflict of Interest}

The authors report no conflicts of interest.

\section{References}

1. Human Genomics in Global Health, World Health Organisation. (Accessed 2016, at http://www.who.int/genomics/public/ geneticdiseases/en/index2.html).

2. Vichinsky EP. Changing patterns of thalassemia worldwide. Ann N Y AcadSci. 2005 Nov 1;1054(1):18-24.

3. Yazdi kh, Sanagou A, Joybari L. Problems and their coping with them in families of patients with thalassemia in Golestan province.2007. J Gorgan Univ Med Sci. vol1;9(2):71-5(In Persian).

4. Abolghasemi H, Amid A, Zeinali S, Radfar MH, Eshghi P, Rahiminejad MS, Ehsani MA, Najmabadi H, Akbari MT, Afrasiabi A, Akhavan-Niaki H. Thalassemia in Iran: epidemiology, prevention, and management. . J PedHematolOncol. 2007 ; 1;29(4):233-8.

5. Davis B. Fertility and pregnancy in thalassaemia and sickle cell disease. The UK guidelines. Thalassemia Reports. 2014 Dec 4;4(3).
6. Thompson AA, Kim HY, Singer ST, Vichinsky E, Eile J, Yamashita R, Giardina PJ, Olivieri N, Parmar N, Trachtenberg F, Neufeld EJ. Pregnancy outcomes in women with thalassemia in North America and the United Kingdom. Am. J. Hematol. 2013 .1;88(9):771-3.

7. Sheiner E, Levy A, Yerushalmi R, Katz M. Beta-thalassemia minor during pregnancy. Am J Obstet Gynecol. 2004 .1;103(6):12737.

8. Hanprasertpong T, Kor-anantakul O, Leetanaporn R, Suntharasaj T, Suwanrath C, Pruksanusak N, Pranpanus S. Pregnancy outcomes amongst thalassemia traits. Arch GynecolObstet. 2013 Nov 1;288(5):1051-4.

9. Amooee S, Samsami A, Jahanbakhsh J, Karimi M. The pregnancy outcome in patients with minor $\beta$-thalassemia.IJRM. 2011;9(1):9.

10. Matão L, Borges de Miranda ME, Freitas D, Fátima MI. Entre o desejo, direito e medo de 
ser mãe após soropositividade para o HIV. Enfermería global. 2014 Apr;34:467-80.

11. Braga Cartaxo CM, Domingues do Nascimento CA, Menino Diniz CM, Rodrigues Pinheiro de Araujo Brasil D, da Silva IF. Gestantes portadoras de HIV/ AIDS: Aspectos psicológicos sobre a prevenção da transmissão vertical.SciELO. 2013;18(3);419-427

12. Mayer B, Trommsdorff G. Adolescents' value of children and their intentions to have children: a cross-cultural and multilevel analysis. J Cross Cult Psychol. 2010;41(56):671-89.

13. Ntozi JP. The desire for children in tropical Africa: the influence of relatives on fertility decisions in Ankole, Uganda. J Biosoc Sci Oct. 1990;22(4):433-46.

14. Siegenthaler AL, Bigner JJ. The value of children to lesbian and non-lesbian mothers. J Homosex. 2000 ;10;39(2):73-91.

15. Levandowski BA, Kalilani-Phiri L, Kachale F, Awah P, Kangaude G, Mhango C. Investigating social consequences of unwanted pregnancy and unsafe abortion in Malawi: the role of stigma. Int J Gynaecol Obstet. $2012 ; 1 ; 118($ S2).

16. Glenn EN, Chang G, Forcey LR. Mothering: Ideology, experience, and agency. New York, NY: Routledge; 2016 ;387

17. Morgan SP, Bachrach CA. Is the Theory of Planned Behaviour an appropriate model for human fertility?. Vienna Yearbook of Population Research. 2011 ;(1);9:11 8

18. Ahmed S, Bryant LD, Cole P. Midwives' perceptions of their role as facilitators of informed choice in antenatal screening. Midwifery. 2013 ; 1;29(7):745-50.

19. Hashemieh M, Naghadeh HT, Namini MT, Neamatzadeh H, Dehshal MH. The Iran thalassemia prevention program: success or failure?. Iran J Ped Hematol Oncol. 2015;5(3):161.

20. Sandelowski M, Barroso J. Motherhood in the context of maternal HIV infection. Research in nursing \& health. 2003 Dec;26(6):470-82.

21. Thomas GM. An elephant in the consultation room?: configuring Down syndrome in British antenatal care. Med Anthropol Q. 2016 Jun;30(2):238-58.

22. Ross EJ. 'I think it's self-preservation': risk perception and secrecy in early pregnancy. Health Risk Soc. 2015 ;18;17(5-6):329-48.
23. Lupton D. The social worlds of the unborn. $2013 ;(19), 153$

24. Inhorn MC, editor. Reproductive disruptions: Gender, technology, and biopolitics in the new millennium. New York, NY; Berghahn books; $2007 ;(1) ; 239$

25. Graneheim UH, Lundman B. Qualitative content analysis in nursing research: concepts, procedures and measures to achieve trustworthiness. Nurs Educ Today. $2004 ; 24(2): 105-12$.

26. Mahmoudi NH, Nakhjavani N, Eshraghi P. Attitude of Minor Thalassemia Couples on legal abortion of embryo thalassemia.J Mashhad Univ Med Sci 2013; 23;56(3):17781 (In Persian).

27. Lincoln YS, Guba EG. Naturalistic inquiry. Sage; 1985.

28. Aujoulat I, Libion F, Berrewaerts J, Noirhomme-Renard F, Deccache A. Adolescent mothers' perspectives regarding their own psychosocial and health needs: a qualitative exploratory study in Belgium. Patient Educ Counsel. 2010 ;81(3):448-53.

29. Shosha GM. Needs and concerns of Jordanian mothers with thalassemic children: A Qualitative Study. J Am Sci. 2014;10(1):11-6.

30. James S, Van Rooyen D, Juanita Strümpher D. Experiences of teenage pregnancy among Xhosa families. J Midwifery. 2012;4(3):1-81

31. Jantan AW, Muhammad SA, Mat Zain N, Abdul Rahman S, Mohamed Z, Rahim A, Faszrul A, Wan Su K. Thalassaemia: a study on the perception of patients and family members. Med J Malaysia. 2011;66(4):32634.

32. Ishfaq K, Ali AA, Hashmi M. Mothers' Awareness and Experiences of Having a Thalassemic Child: A Qualitative Approach. Pakistan Journal of Social Sciences (PJSS). 2015;35(1). 109-121

33. Ghazanfari Z, Arab M, Forouzi M, POURABOULI B. Knowledge level and education needs of thalassemic childern's parents of Kerman city. IJCCN,2010; ; 3(3):99-103

34. Prasomsuk S, Jetsrisuparp A, Ratanasiri T, Ratanasiri A. Lived experiences of mothers caring for children with thalassemia major in Thailand. JSPN. 2007;12(1):13-23. 